\title{
Clients of Commercial Sex Workers in Zambia: Prevalence, Frequency, and Risk Factors
}

\author{
Pauline M. Leclerc ${ }^{*}$ and Michel Garenne
}

Institut Pasteur, Unité d'Epidémiologie des Maladies Emergentes, Paris, France

\begin{abstract}
The study analyses the profile and the behavior of male clients of female commercial sex workers (CSW's) in Zambia. According to the Zambia 2001 DHS survey, among the 1730 men sexually active during the past year, the proportion who used the services of CSW's in the 12 months prior to the survey was $13.2 \%$. This proportion varied very much with age and marital status. Most clients of CSW's were unmarried men. Several demographic, socioeconomic, and personal factors were identified, which effect differed according to marital status. Using the services of CSW's appears as a very heterogeneous behavior, with major differences according to age, marital status, socioeconomic status, and personal attitudes. A multiple correspondence analysis revealed that attitudes (drinking, smoking, wife-beating) were orthogonal to age, marital status and socioeconomic status. The frequency of visits to CSW's was fitted with a Poisson model. On the average, clients visited CSW's 3.8 times a year.
\end{abstract}

Keywords: Sexual behavior, commercial sex, risk factors, marital status, socioeconomic status, attitudes, multivariate analysis, multiple correspondence analysis, Zambia, Sub-Saharan Africa.

\section{INTRODUCTION}

Efforts to understand the dynamics of the HIV/AIDS epidemics in Africa led to major research activities in a wide variety of fields in the social and medical sciences, ranging from anthropology and demography to epidemiology and virology, and many others. In particular, many studies on sexual behavior were conducted as a result, a domain which was poorly explored before 1980 and which is a key to understand the transmission of HIV and other sexually transmitted infections (STI's). A series of sexual behavior surveys were conducted in the late 1980's [1] under the aegis of the World Health Organization, and questions on sexual behavior became a standard in many Demographic and Health Surveys (DHS)[2]. Many small scale surveys on male or female sexual behaviors were also conducted throughout Africa, among high risk groups as well as in the general population [3-6].

Commercial sex is a specific behavior that has drawn much attention from researchers, especially in the early years of the HIV epidemics, because many commercial sex workers (CSW's) became infected within a few years after the onset of the epidemic [7-12]. Further investigations led to better understand the complexity of this behavior, with very large differences among countries. This complexity found between countries also applies to variations within the same country: use of commercial sex varies very much with area of residence, and seems to be particularly widespread in large cities, in big harbors, around the mines, in large industrial centers, and along major trade routes [13-15].

*Address correspondence to this author at the Institut Pasteur, Epidémiologie des Maladies Emergentes, 25 rue du Docteur Roux, 75724, Paris, France; Tel: +33-1-40-61-39-65; Fax: +33-1-45-68-88-76;

E-mail: leclerc@pasteur.fr
If much has been learned on female CSW's, much less research has been conducted on their male clients. In a systematic search, we found only a few articles devoted to male clients of CSW's in Africa [16-18].

This paper aims at filling this gap, by focusing on men, and describing at the same time their behavior and the associated risk factors and socioeconomic correlates from a case study in Zambia. This study is a part of a larger project aiming at building a micro-simulation model describing the HIV epidemic in Zambia. For this modeling exercise, it was important to have precise data on users of CSW's services by detailed age groups and marital status.

\section{THE CONTEXT}

Zambia is located in Central Africa, not far from the epicenter of the HIV epidemic, which probably explains why HIV arrived so early in the country. The history of human settlement is complex, with some 80 ethnic groups recorded, who came at various periods from neighboring countries. The country's recent history is dominated by the discovery of copper mines in 1927, which had many economic, demographic and social consequences: rapid urbanization and industrialization, income growth, and major migration flows towards the "Copperbelt" province, all factors favoring the development of commercial sex. However, the society was not affected by economic development as much as Southern African countries, and it remained closer to its northern and eastern neighbors in terms of demographic behavior: early age at marriage (18.1 years), high fertility $(\mathrm{TFR}=5.9$ children per woman), moderate contraceptive use (25\%), medium prevalence of polygyny $(16 \%)$ [19]. HIV seroprevalence in 2001 was $16 \%$, which is higher than its Northern and Eastern neighbors (Congo, Tanzania), but lower than its Southern neighbors (Botswana, Zimbabwe). 


\section{MATERIAL AND METHODS}

\section{Study Population}

Data used for this analysis come from the Demographic and Health Survey (DHS) conducted in Zambia in 2001, on a nationally representative sample of 2,145 men aged 15-59 years [19]. This survey provides data on numerous demographic and health characteristics, as well as on sexual behavior. Various elements of sexual behavior are available in DHS surveys, and in the Zambia 2001 survey, several relevant questions were asked to men aged 15-59: whether they "ever paid for sex" (Q445), and if yes "how long ago was the last time they paid for sex" (Q446). However these questions were restricted to men who had intercourse in the past 12 months, introducing therefore a small bias (some men who had no intercourse in the past 12 months could have ever paid for sex previously). From these questions, a new variable was created "Has paid for sex in the last 12 months", with the corresponding "duration since last time paid for sex". The DHS surveys also include a variety of demographic factors, socioeconomic correlates, and personal factors that could be used as potential risk factors of visiting a commercial sex worker.

\section{Methods}

The reconstructed variable ("paid for sex in the last 12 months") allows at the same time to study the frequency of using CSW's services over a period of one year, and to study its risk factors.

In addition to basic data on prevalence, an attempt was made to better describe the men's behavior. Firstly, the comparison of "ever paid for sex" and "paid for sex in the last 12 months" gives a clue on when men first became clients of CSW's, and allows to describe age and cohort effects. Note that a full scale life-table analysis was not possible since the age at first encounter with a CSW was not provided. Secondly, the distribution of "time since last paid for sex", allowed to estimate the mean and variance of the yearly number of encounters for the clients. This was done by assuming that the observed open interval distribution follows a Poisson distribution, and by fitting its parameters using a maximum likelihood procedure.

Thirdly, basic univariate analysis of the risk factors of using CSW's services was conducted by comparing the clients in the past 12 months (cases) with the other men who had intercourse during the past 12 months but did not pay for sex (controls). Several potential risk factors were tested in univariate analysis. First, classic socio-demographic variables were tested: age (in linear pattern, by year), place of residence (urban areas in Copperbelt/Lusaka, other urban areas, rural areas), ethnicity (lumping together ethnic groups from the three main regions: south-west, center, and northeast), religion (Christian or not), level of education (no education or primary education versus secondary or higher education), current work status (employed or not), and time away from home in the last year (more than one month or less). Marital status and fertility status were analyzed in depth, because of their close relationship with sexual behavior: current marital status (married or not), number of wives, marital duration (in linear by 5 -years group), number of living children $(0,1$ or more than 1$)$, time since first inter- course (in linear by 5-years group), number of partners in the last 12 months ( 1 or more than 1). Finally, we added personal variables which could characterize an attitude or a risky behavior: contraceptive use, condom use, smoking habits (currently smoking), drinking habits (drunk at least once in the last 3 months), and wife-beating attitude. The wife-beating attitude was calculated from five different questions in the DHS questionnaire. Each man was asked if wifebeating is justified in the following cases: "wife goes out without telling him", "neglects the children", "argues with him", "refuses to have sex with him", "burns the food". If the answer to at least one of these questions was positive, the man was considered having a "wife-beating attitude". In addition, a wealth index was built, by adding the presence of 13 modern goods and amenities in the household, on the model of a wealth index described elsewhere [20]. Note that this wealth index, which ranges from 0 to 13 , is an absolute measure of poverty, and different from the wealth quintiles provided by the DHS surveys. For the univariate analysis, $\chi^{2}$ tests were computed using standard formulae for cross tabulation.

When testing variables and their interactions, it appeared that marital status (married versus single) strongly interacted with several others: age, use of contraception, use of condom, number of partners in the last 12 months, and place of residence. Therefore, two models were built, considering separately currently married men from unmarried men. As a consequence, the variable "number of wives" was modified in "monogamous/polygamous" for the married group, and the variable "ever married" was added as a potential risk factor for the unmarried group. Moreover, the "number of partners in the last 12 months", previously comparing "1 partner" with "2 or more partners", was dropped in the final analysis of the married group because of its relationship with visiting a CSW in the last 12 months (married men who visited a CSW were all in the 2-and-more-partners group).

Likewise, the multivariate analysis of risk factors was conducted separately in each group (married and unmarried), using a linear-logistic regression model. In the exploratory phase, we included all variables testing with a P-value $<0.25$ in the $\chi^{2}$ tests done in the univariate analysis. We used a backward stepwise procedure, dropping each variable one by one, beginning with the less significant, and in the final analysis we kept only variables with a P-value less than 0.05 . In the group analysis, eight men (4 married and 4 unmarried) were deleted because of inconsistencies or missing values for one of the variables. The Odds-Ratios (ORs) presented in the tables are the exponential values of the coefficients from the logistic regression model.

Fourthly, a "multiple correspondence analysis" (MCA) was conducted in order to reveal the main structures of the male population with respect to commercial sex behavior. This analysis nicely supplements the logistic regression. The aim of the MCA is to identify the associations between use of commercial sex and the various factors, and it allows to group variables. If successful, the MCA will explain most of the variance in the study population. All variables seen in risk factors analysis were included in this analysis. "Paid for sex in the last 12 months" was added as a supplementary variable, which means that it was not taken into account to calculate the eigen values and the factorial axes. Note that 
we did not analyze the married and unmarried groups separately in order to figure out the importance of the marital situation. For this part, a large table was constructed, with individuals in rows and the various risk factor variables in columns, one column for each modality described above.

The data were analyzed with Intercooled Stata 9, and the MCA was done with Intercooled Stata 10.

\section{RESULTS}

Among the 2145 men interviewed in the 2001 Zambia DHS, 212 never had sex (9.88\%), 203 men who ever had sex did not have intercourse in the past year, and 1730 (80.65\%) had sex in the past year.

The study of risk factors is therefore based on 1730 men sexually active in the last year. Among them, 498 (28.8\%) were unmarried at the time of the interview, with a median age of 20 years (range from 15 to 55 years), and 1232 $(71.2 \%)$ were married, with a median age of 35 years (range from 17 to 59 years).

\section{Prevalence and Time Trends}

Among the 1730 men who were sexually active last year, $26.8 \%$ had ever paid for sex, and $13.2 \%$ had paid for sex in the past 12 months (Table $\mathbf{1}$ ).

The distribution of men according to their sexual behavior is displayed in Fig. (1), which shows at the same time the entry into sexual life (age 15-24) and the steady state after age 25 . The proportion of men who never had sex drops from about $50 \%$ at age $15-16$ to very small values by age 25 (average of $0.6 \%$ at age $25-59$ ). The proportion who had no sexual partner in the past 12 months is higher for the young adults $(17.1 \%$ age below age 25$)$ and lower $(5.1 \%)$ above age 25 , and quite constant with age up to age 59 . The proportion of men who ever paid for sex is already high at age 15$16(10 \%)$, and increases rapidly up to age $25(26 \%)$. After age 25 , this proportion is decreasing with birth cohorts, which suggests that using CSW's services tended to increase somewhat over the years in Zambia, from $20 \%$ for men born in $1940-1949$ to $26 \%$ for men born around 1975 . The high proportion at age 25 and the decline thereafter suggests that most of the behavior is acquired at an early age, and primarily before marriage since the median age at first marriage for men is 23.4 years in Zambia, and that when men have not had intercourse with CSW's before age 25 they are unlikely to do so afterwards. The high proportion at age 25 is consistent with a rate of entry into the behavior of about $2.7 \%$ per year between age 12 and $17,1.7 \%$ per year between age 17 and 22 , and smaller thereafter. Compared with the rate of entry into first intercourse (ranging from 8 to $24 \%$ per year according to age), this suggests that a large proportion of men's sexual encounters early in life are in fact with CSW's, possibly as high as a fourth for the very young men (15-17 years old), and some 5 to $10 \%$ for the late teenagers (18-19 years old).

\section{Univariate Analysis of Risk Factors}

Unmarried men were far more likely to visit a CSW $(29.3 \%)$ than married men $(6.7 \%)$ the difference being highly significant $(\mathrm{P}<0.001)$ (Table 1).

Table 2 displays the raw effect of each variable investigated on the prevalence of visits to CSW's in the past year, according to marital status. Age had an effect for the married men, with a decline in visits to CSW's with age $(\mathrm{P}<0.001)$, whereas it had no effect for unmarried men. The effect of place of residence was strong for married men, and borderline for unmarried men. Furthermore the effect was different for the two strata: compared with rural areas, other urban areas had a lower risk for unmarried men, and a higher risk for married men, whereas the urban areas of Copperbelt and Lusaka had a lower risk for both strata. The effect of ethnicity (large groups) was small, with a reduced risk for groups living in the North-eastern areas (borderline significance). The effect of Christian religion was not statistically significant. For education, only the higher categories (secondary education or more) showed a reduced risk, and was statistically significant only for unmarried men. Being away from home more than a month per year increased somewhat the risk in a consistent way, but the differences were not significant, and the same was true for work status. Wealth had a large linear effect for unmarried men, with a strong reduction in risk for each step of the scale, from 1 for the poorest category $(0-1)$ to 0.15 for the wealthiest category $(8+)$, but no effect for the married men.

With respect to marital status and fertility variables, being ever married for unmarried men and being polygamous for married men had no significant effect. Longer marital duration reduced the risk for married men (as for age), but had no effect for the divorced and widowed. Time since first intercourse had the same effect as age for both the married men and unmarried men, and appeared largely redundant in this case. Using contraception or condoms had a large effect for married men ( $\mathrm{P}<0.001$ in both cases), but no effect for unmarried men.

The effect of personal attitudes was rather large compared to other risk factors. The "wife-beating attitude" increased the risk for married men $(\mathrm{OR}=2.48,95 \% \mathrm{CI}=[1.40$ $4.40])$ as well as for the unmarried men $(\mathrm{OR}=1.91 ; 95 \% \mathrm{CI}$ $=[1.12-3.26])$. Smoking and drinking also increased the risk

Table 1. Sample Size and Basic Indicators (Sexually Active Men), Zambia 2001

\begin{tabular}{|c|c|c|c|}
\hline & Unmarried Men & Married Men & Combined Sample \\
\hline Nb of men sexually active & 498 & 1232 & 1730 \\
\hline Proportion who paid for sex in past 12 months & $29.3 \%$ & $6.7 \%$ & $13.2 \%$ \\
\hline Mean duration since last time paid for sex & 84 days & 121 days & 96 days \\
\hline
\end{tabular}




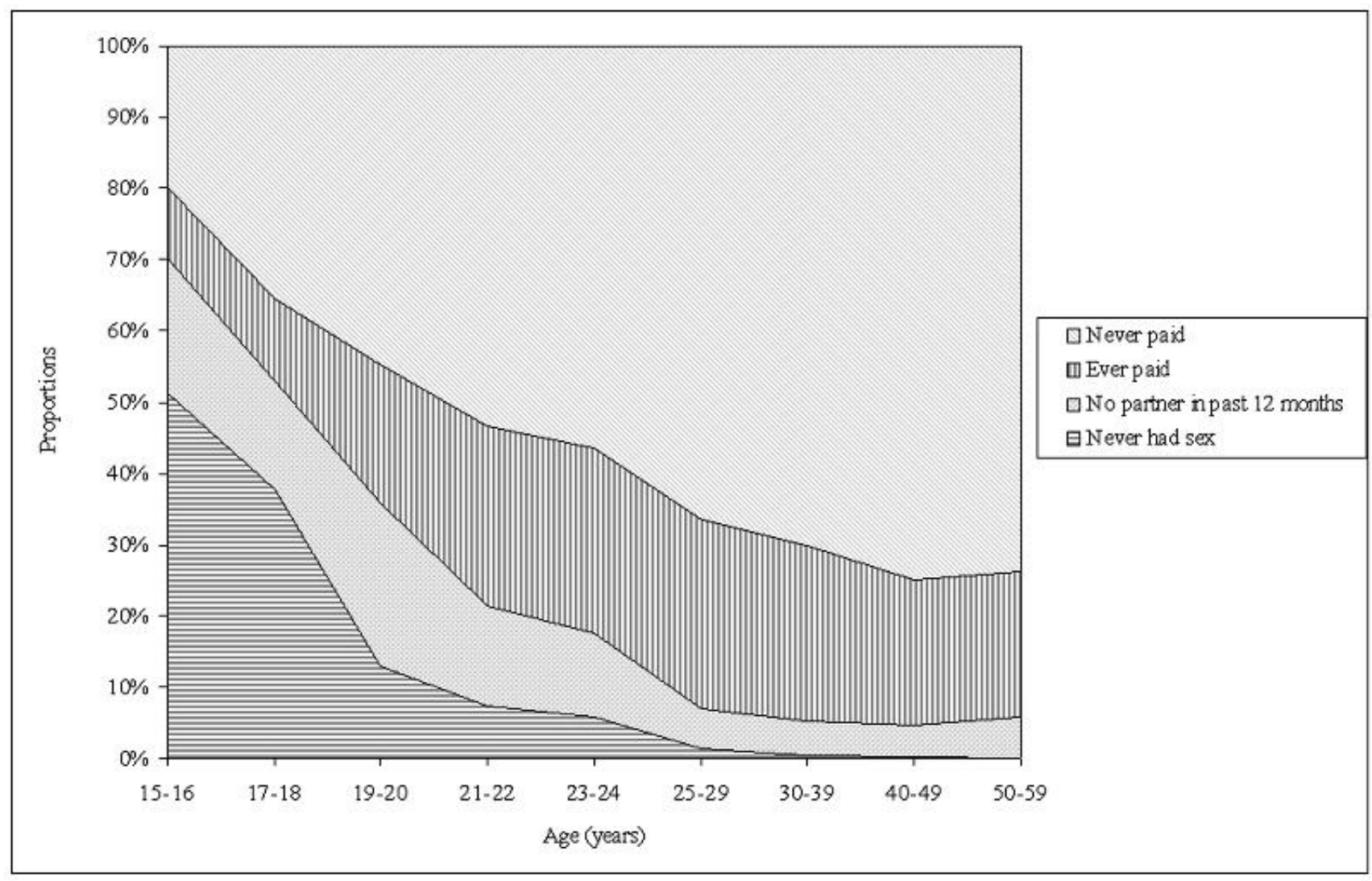

Fig. (1). Distribution of the male population according to sexual behavior, Zambia 2001.

in a similar way in both groups, although the level of significance was low, except for drinking in the married group where the association became significant $(\mathrm{P}=0.11$ and $\mathrm{P}=0.08$ for smoking, and $\mathrm{P}=0.11$ and $\mathrm{P}=0.02$ for drinking, respectively for unmarried and married groups).

In summary, age, marital status, and socioeconomic factors seem to play a different role for married and unmarried men, with an overall tendency towards lower risk for higher socioeconomic status and for older persons, whereas the personal factors tended to have consistent effects in both groups.

\section{Multivariate Analysis of Risk Factors}

In the unmarried group, only four variables remained significantly associated with visiting a CSW in the last 12 months (Table 3). Having two or more sexual partners in the last 12 months and being drunk at least once in the last 3 months were associated with an increased risk of visiting a $\mathrm{CSW}$ in the last year $(\mathrm{OR}=2.97$ and $\mathrm{P}<0.001$; $\mathrm{OR}=1.81$ and $\mathrm{P}=0.01$ respectively). On the contrary, higher education and wealth were associated with lower risks $(\mathrm{OR}=0.53$ and $\mathrm{P}=0.01$ for education; OR declining from 1.00 to 0.19 , with $\mathrm{P}=0.004$ for wealth index ranging from $0-1$ to $8+$ ). Note that these odds ratios hardly changed from the univariate analysis, indicating that these variables were largely independent, although the wife-beating attitude became borderline significant $(\mathrm{P}=0.06)$.

In the married group, seven variables remained significant in the multivariate analysis (Table 4). Here again the odds ratios were similar to those found in the univariate analysis, and the main difference was that the effect of level of education became larger and significant $(\mathrm{OR}=0.51$, $\mathrm{P}=0.014$ ), and close to that found for the unmarried men. The only other factor reducing the risk was age $(\mathrm{OR}=0.94$ per unit, $\mathrm{P}<0.001$ ). Men who used contraception and condom were more likely to visit a $\mathrm{CSW}(\mathrm{OR}=2.93$ and $\mathrm{P}<0.001$, $\mathrm{OR}=2.50$ and $\mathrm{P}<0.001$ respectively). Likewise, men with a wife-beating attitude also had increased risk $(\mathrm{OR}=2.50$; $\mathrm{P}=0.003)$, as was the case for smokers $(\mathrm{OR}=1.85 ; \mathrm{P}=0.014)$. Last, living in other urban areas had an increasing risk $(\mathrm{OR}=$ $3.14,95 \% \mathrm{CI}=[1.68-5.85])$.

With the sole exception of level of education, the significant risk factors for unmarried and married men were different, which justifies a posteriori the use of two different strata for the analysis.

\section{Multiple Correspondence Analysis}

The first four dimensions of the MCA explained $83 \%$ of the inertia. The first dimension, accounted for $69 \%$ of the inertia, and was associated with age and marital status. The main variables contributing positively were: unmarried, aged less than 30 years ("Age $<30$ "), having no child, never married, first intercourse less than 10 years ago ("Sextime $<10$ "), not currently working. Variables contributing negatively were: married, aged 30 years and above ("Age $>30$ "), having more than one child ("Nb children $>1$ "), married for more than 30 years ("Married> 30"), first intercourse more than 20 years ago ("Sextime> 20"). The variable "Paid for sex in the last 12 months" varied somewhat along this axis, linking a 
Table 2. Univariate Analysis of the Risk Factors of Visiting a Commercial Sex Worker in the Last 12 Months, by Strata (Married and Unmarried), Zambia 2001

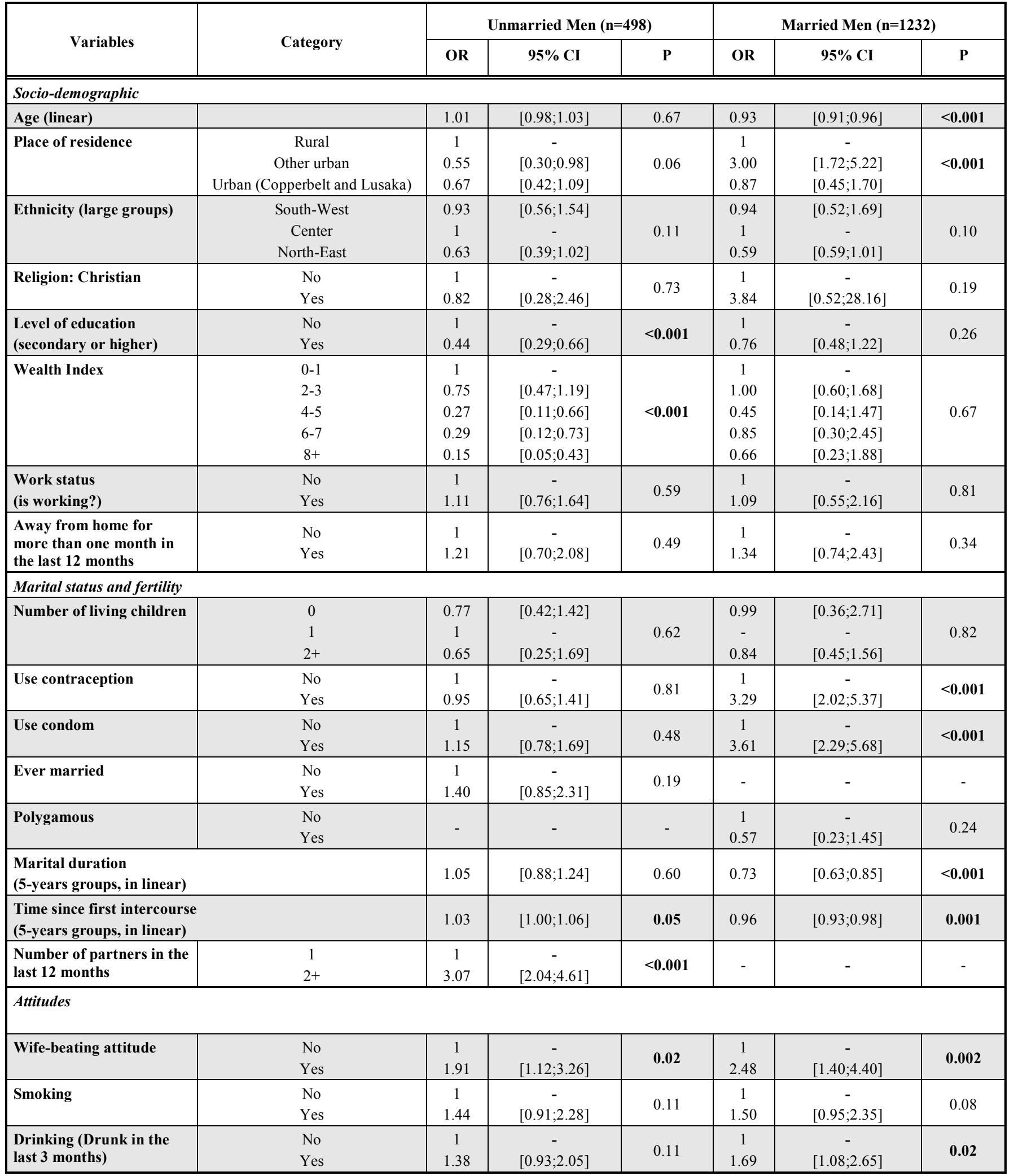

positive response with the younger and unmarried men, and a negative response with older, married men with children (Fig. 2).
The second dimension accounted for $8 \%$ of the inertia and was associated with socioeconomic status (Fig. 2). The main variables contributing positively were: rural residence, poorer strata (Wealth index 0-1), no education, no use of 
Table 3. Multivariate Analysis of the Risk Factors of Visiting a Commercial Sex Worker in the Last 12 Months, Unmarried Men $(n=494)$, Zambia 2001

\begin{tabular}{|c|c|c|c|c|}
\hline Variables & Category & OR & $95 \% \mathrm{CI}$ & $\mathbf{P}$ \\
\hline Number of partners in the last 12 months & $\begin{array}{c}1 \\
2+\end{array}$ & $\begin{array}{c}1 \\
2.97\end{array}$ & $\begin{array}{c}- \\
{[1.93 ; 4.57]}\end{array}$ & $<0.001$ \\
\hline Level of education (secondary or higher) & $\begin{array}{l}\text { No } \\
\text { Yes }\end{array}$ & $\begin{array}{c}1 \\
0.53\end{array}$ & $\begin{array}{c}- \\
{[0.32 ; 0.86]}\end{array}$ & 0.01 \\
\hline Drunk in the last 3 months & $\begin{array}{l}\text { No } \\
\text { Yes }\end{array}$ & $\begin{array}{c}1 \\
1.81\end{array}$ & $\begin{array}{c}- \\
{[1.15 ; 2.85]}\end{array}$ & 0.01 \\
\hline Wealth Index & $\begin{array}{c}0-1 \\
2-3 \\
4-5 \\
6-7 \\
8+\end{array}$ & $\begin{array}{c}1 \\
0.80 \\
0.37 \\
0.32 \\
0.19\end{array}$ & $\begin{array}{c}- \\
{[0.48 ; 1.31]} \\
{[0.14 ; 0.95]} \\
{[0.12 ; 0.85]} \\
{[0.06 ; 0.54]}\end{array}$ & 0.004 \\
\hline
\end{tabular}

Table 4. Multivariate Analysis of the Risk Factors of Visiting a Commercial Sex Worker in the Last 12 Months, Currently Married Men (n=1228), Zambia 2001

\begin{tabular}{|c|c|c|c|c|}
\hline Variables & Category & OR & $95 \% \mathrm{CI}$ & $\mathbf{P}$ \\
\hline Age (linear) & & 0.94 & {$[0.91 ; 0.97]$} & $<0.001$ \\
\hline Use contraception & $\begin{array}{l}\text { No } \\
\text { Yes }\end{array}$ & $\begin{array}{c}1 \\
2.93\end{array}$ & $\begin{array}{c}- \\
{[1.71 ; 5.02]}\end{array}$ & $<0.001$ \\
\hline Wife beating attitude & $\begin{array}{l}\text { No } \\
\text { Yes }\end{array}$ & $\begin{array}{c}1 \\
2.50\end{array}$ & $\begin{array}{c}- \\
{[1.38 ; 4.54]}\end{array}$ & 0.003 \\
\hline Smoking & $\begin{array}{l}\text { No } \\
\text { Yes }\end{array}$ & $\begin{array}{c}1 \\
1.85\end{array}$ & $\begin{array}{c}- \\
{[1.13 ; 3.01]}\end{array}$ & 0.014 \\
\hline
\end{tabular}

contraception ("No_Contrac"), religion other than Christian. Variables contributing negatively were: urban residence, especially Lusaka, higher wealth, higher level or education, and contraceptive use. This axis had little relationship with being a client of CSW (both categories were close to the origin), though the "paid for sex" category was on the positive side.

The third dimension was more complex and showed interactions between age, marital status and socioeconomic status (not shown). The negative side corresponded to medium categories of demographic variables, related to young married adults (One child, marital duration lower than 15 years, first intercourse between 10 and 20 years ago, age lower than 30). The positive side focused on older persons who had a higher level of wealth (Never married, more than 15 years of marriage, age higher or equal to 30 , wealth index 4 and above). It also had only a weak relationship with "paid for sex", which here was on the negative side.
The fourth dimension clearly represented attitudes and behavior (Fig. 2). Positive contributions came from smoking, drinking, having more than one partner, condom use, and living in other urban areas. Negative contributions came from the opposite categories, and medium wealth (4-5). Visiting CSW in the last year was well represented on this axis, with a very high positive value, revealing again its strong association with risky behaviors. Note that this "attitude" dimension was orthogonal to the others representing age, marital status and socioeconomic status.

\section{Frequency of Visits to CSW's}

The adequacy of the distribution of the annual number of visits to a CSW to a Poisson distribution was tested by analyzing the waiting time, the sole information available in the DHS survey. The cumulated distribution of time since last paid for sex could be fitted with an exponential model, which indicates that the process followed a Poisson law (Fig. 3). 


\section{First dimension}

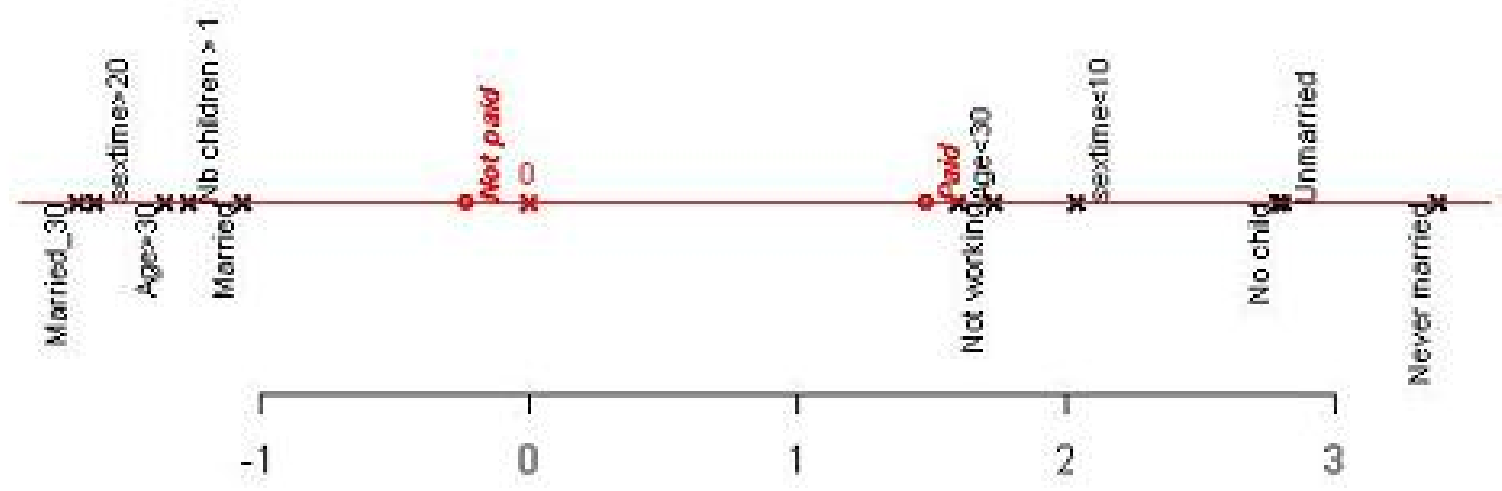

Second dimension

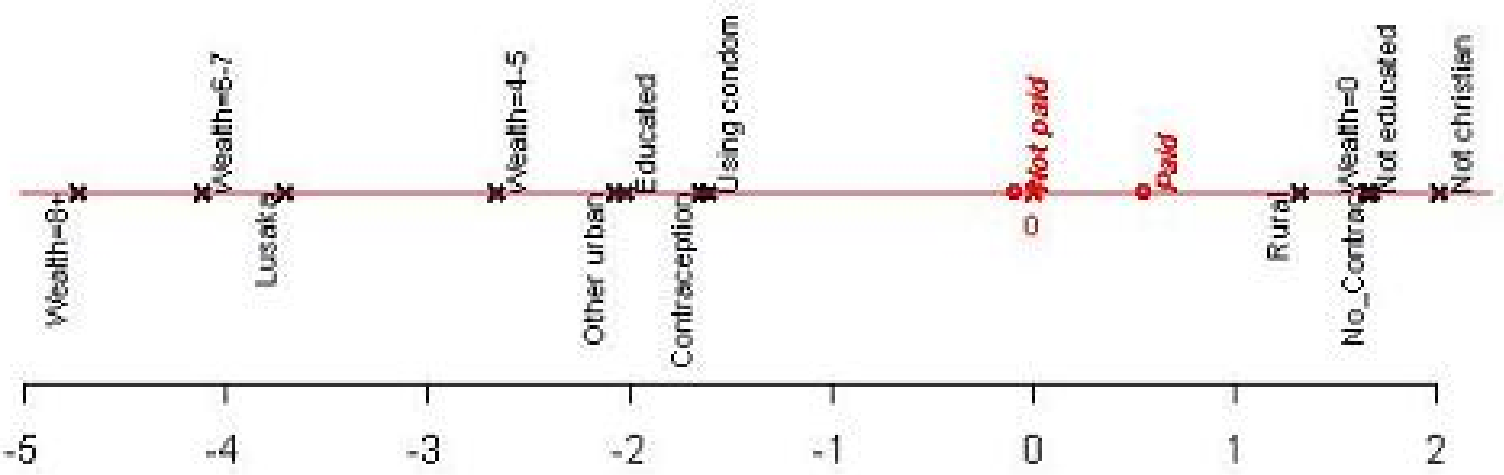

Fourth dimension

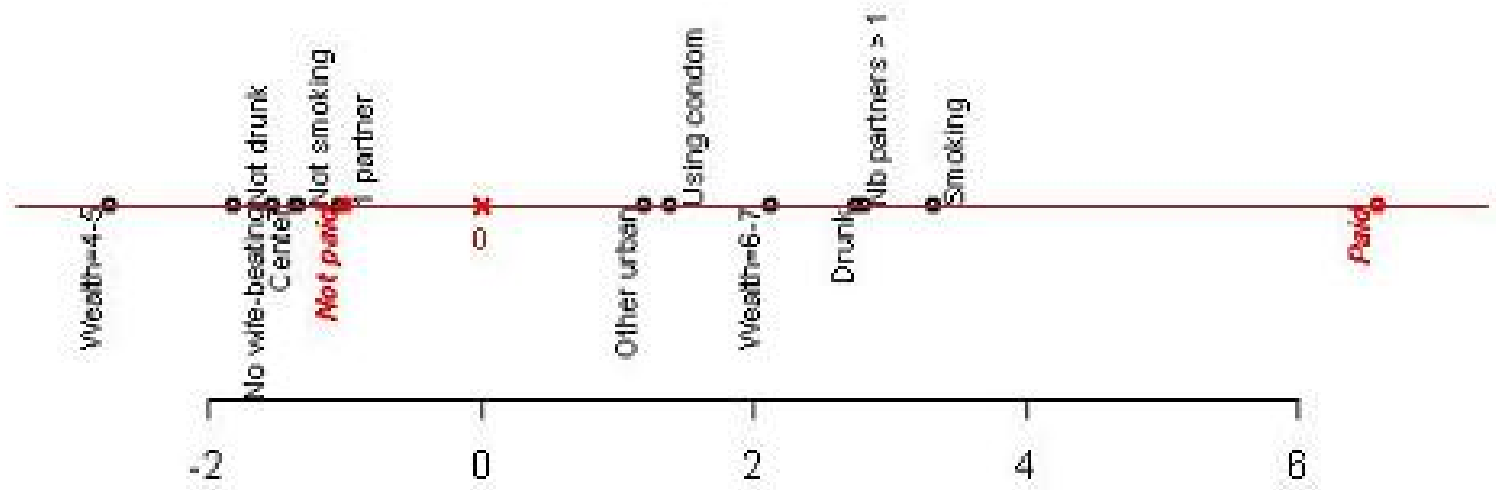

Fig. (2). Multiple Correspondence Analysis: Dimensions one, two and four. 


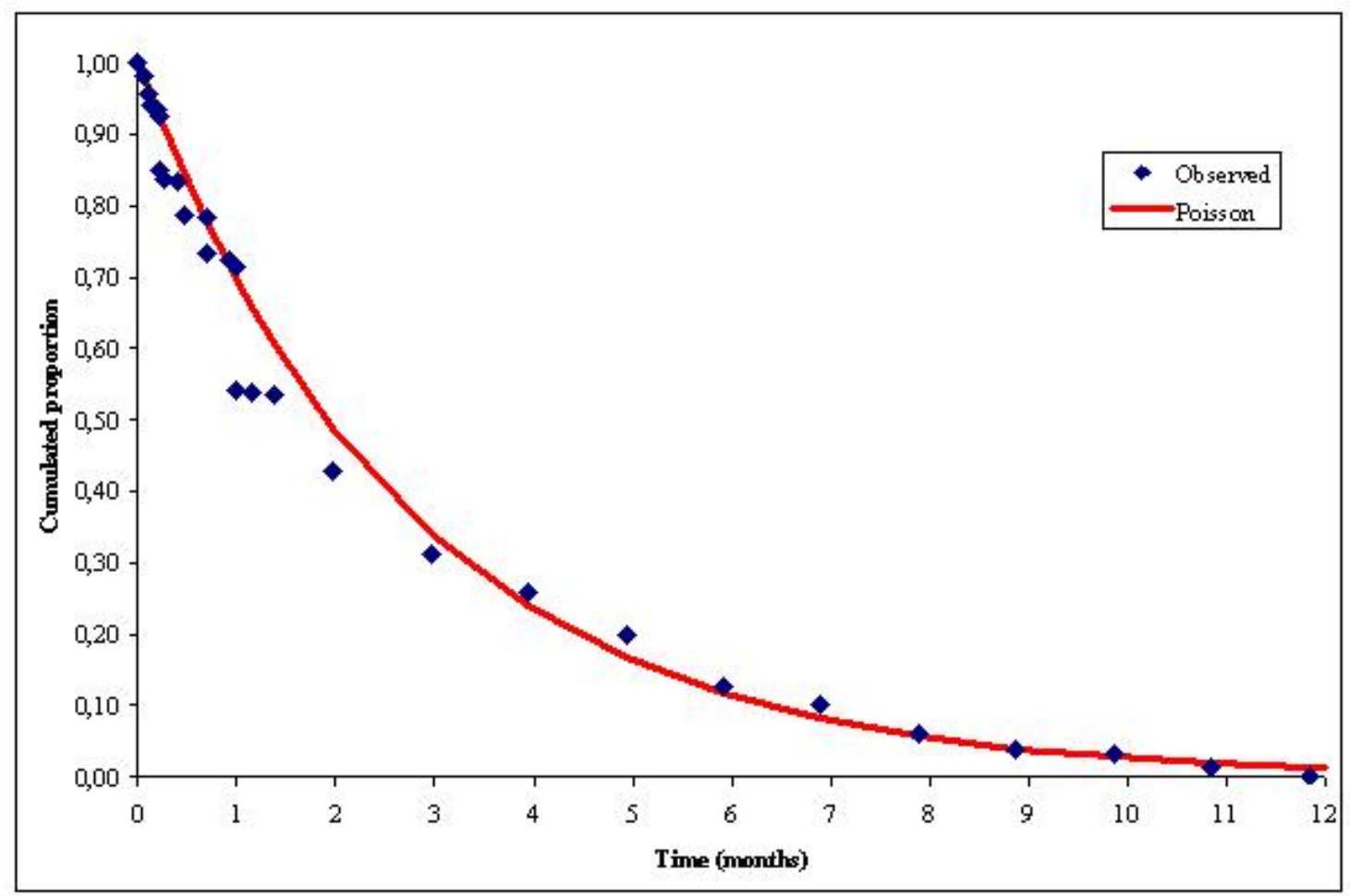

Fig. (3). Cumulated distribution of time since last paid for sex, Zambia, 2001.

The mean waiting time was 96 days, which corresponds to a mean number of visits of 3.8 per year, the parameter of the Poisson distribution, therefore also equal to the variance (Table 1).

As for most parameters investigated in this study, the mean waiting time, and therefore the mean annual number of visits, varied markedly between married and unmarried men. For married men, the mean number of visits was 3.0 per year, and this number was independent of age $(\mathrm{P}=0.271)$, whereas the probability of visiting was strongly dependent on age, as seen above. The pattern was different for the unmarried men: the mean number of visits was higher ( 4.3 per year), and declined significantly with age $(\mathrm{P}=0.001)$, from 5.2 at age 20 to 2.8 at age 40 , whereas the probability of visiting CSW's was independent of age, as seen above.

\section{Estimation of the Number of Encounters}

These parameters were fed into a spreadsheet to estimate the annual number of commercial sex encounters in Zambia. The age structure of the male population, by marital status, was applied to the probability of visiting CSW's, and to the mean number of visits, all calculations being done by single year of age from 15 to 59 , and added for the whole population. This calculation produced some 1,542,000 visits for a total population of 2,331,000 men, among whom 332,000 were clients of CSW's.

Assuming that CSW's have an average of 200 encounters per year, a rough weighted average of women who have about 2 clients per week and those who have about 3 clients per day (depending on the type of CSW's work) [21-24], gives some $7700 \mathrm{CSW}$ 's operating, that is about $1 \%$ of the unmarried female population aged 15-49. Even if these numbers are rough, they provide an order of magnitude of the commercial sex market in Zambia, which were numbers needed for our micro-simulation model.

\section{DISCUSSION}

Zambia has a moderately high prevalence of use of CSW's services, somewhat above average for African countries. Compared with its neighbors, and according to DHS surveys, its prevalence is higher than in Zimbabwe, or Kenya, about the same as in Tanzania, but lower than in Mozambique [2]. Zambia's recent history has been marked by a major economic crisis starting in 1975, which lasted for about 20 years, which could have contributed to a relatively high prevalence of use of CSW's services. In particular increasing poverty after 1975 could possibly explain the rise in prevalence over time, since poverty is associated with increased risk in our analysis. Note that the 1975 crisis had other major demographic impacts, in particular a halt in the urbanization process and a rise in under-five mortality [25].

For practical reasons, the definition of being a client of CSW's was imposed by the 2001 DHS survey, and "paid for sex" was the criteria used. It is beyond the scope of this paper to discuss the reliability of this definition. Many studies were conducted on similar issues, and several definitions of "commercial sex" have been applied in surveys. For instance, Morison et al. [24] show that the percentage of men who had a contact with a sex worker depends on the definition chosen: a woman who exchange sex for money with other partners is not always considered as a "female sex worker" and so, the man does not consider himself as a client. It is striking to note that in the same country, other surveys using other criteria or other population groups provide different estimates of prevalence. For instance, and according to the DHS web site, the 1996 DHS survey found a prevalence of $24 \%$ when including "any type of money, gift 
or favor in return for sex", instead of $10 \%$ for the 2001 DHS. Note also that other sexual behavior surveys conducted in Zambia in 2000 and 2004 also found higher values, because they restricted the samples to "male respondents who have had sex with a non-regular, non-cohabiting partner in the last 12 months".

The risk factors study indicates major differences according to marital status, which are straightforward. The sample size was relatively small, which could explain why some variables were not significant, in particular polygamy. The unmarried situation appeared to be a factor of visiting a CSW, a factor already shown in other studies [17]. With respect to socioeconomic status, the relationship is clear, with increasing risk associated with increasing poverty and low level of education, a pattern which is not always found in other African countries, but which has already been found elsewhere, as in Thailand [26]. The situation of married men in urban areas other than Lusaka and Copperbelt deserves more research, since the associated risk is high and unexpected.

An interesting finding of this investigation is the effect of personal variables, which appear to be independent from marital status and from socioeconomic status, and probably relates to psychological factors. Smoking, drinking and attitude towards violence against women were strong factors of visiting CSW's. Similar results were found, with a different methodology, in the multiple correspondence analysis: "Paid for sex in the last 12 months" was mainly represented in the fourth dimension which displayed the role of negative attitudes and behavior and was orthogonal to age, marital status and social status. These psychological factors are rarely mentioned in the literature. Other factors investigated seem to be due to reverse causality, and should not be taken as proper factors, in particular condom use, a behavior often associated with commercial sex.

Despite relatively high prevalence and early age at visit to CSW's, Zambian men do not seem to get infected with HIV more rapidly than in other countries, given the overall level of HIV seroprevalence. We have shown in another article that the HIV risk attributable to commercial sex was small in five African countries (about 7\%) where epidemics were mature [27]. Although we could not pursue the same investigation for Zambia, because the HIV file could not be linked to the other DHS files, this analysis reinforces the impression that visiting CSW's does not change much the profile of HIV risk for young men in mature epidemics. Note that the proportion of men using condoms was still low in 2001 , with only $16.5 \%$ of our study population declaring using condoms at every sexual contact. No data were available for specific use of condom with commercial sex workers, but Morison et al. found that only $28 \%$ of CSW in Ndola, in the Copperbelt province, were using condom in their most recent contact with clients [24]. Some recent studies found a sexual behaviour change in young people in Zambia [28], probably due to health communications campaigns [29]. Our study suggests that such campaigns should principally focus on younger less educated men.

The Zambian economy took off recently, partly because better economic management, and partly because increased opportunities, in particular a strong increase in copper prices on international markets. The impact that this economic upturn will have in the future on the commercial sex market in Zambia remains to be monitored and analyzed.

\section{REFERENCES}

[1] Cleland JG, Ferry B. World Health Organization. Sexual behaviour and AIDS in the developing world. London: Taylor \& Francis; 1995.

[2] Demographic and Health Surveys. Central board of health, and ORC. Available from: http://www.measuredhs.com.

[3] Ferry B, Carael M, Buve A, et al. Comparison of key parameters of sexual behaviour in four African urban populations with different levels of HIV infection. AIDS 2001; 15: S41-S50.

[4] Gregson S, Nyamukapa CA, Garnett GP, et al. Sexual mixing patterns and sex-differentials in teenage exposure to HIV infection in rural Zimbabwe. Lancet 2002; 359: 1896-903.

[5] Konde-Lule JK, Wawer MJ, Sewankambo NK, et al. Adolescents, sexual behaviour and HIV-1 in rural Rakai district, Uganda. AIDS 1997; 11: 791-9.

[6] Lagarde E, Auvert B, Carael M, et al. Concurrent sexual partnerships and HIV prevalence in five urban communities of subSaharan Africa. AIDS 2001; 15: 877-84.

[7] Piot P, Laga M. Prostitutes: A high risk group for HIV infection? Soz Praventivmed 1988; 33: 336-9.

[8] Bigot A, Bodeus M, Burtonboy G, Ahouignan G, Zohoun I. Prevalence of HIV infection among prostitutes in Benin (West Africa). J Acquir Immune Defic Syndr 1992; 5: 317-9.

[9] Piot P, Plummer FA, Rey MA, et al. Retrospective seroepidemiology of AIDS virus infection in Nairobi populations. J Infect Dis 1987; 155: 1108-12.

[10] Nzila N, Laga M, Thiam MA, et al. HIV and other sexually transmitted diseases among female prostitutes in Kinshasa. AIDS 1991; 5: 715-21.

[11] Djomand G, Greenberg AE, Sassan-Morokro M, et al. The epidemic of HIV/AIDS in Abidjan, Cote d'Ivoire: A review of data collected by Projet RETRO-CI from 1987 to 1993. J Acquir Immune Defic Syndr Hum Retrovirol 1995; 10: 358-65.

[12] Mann JM, Nzilambi N, Piot P, et al. HIV infection and associated risk factors in female prostitutes in Kinshasa, Zaire. AIDS 1988; 2: 249-54.

[13] Gysels M, Pool R, Bwanika K. Truck drivers, middlemen and commercial sex workers: AIDS and the mediation of sex in south west Uganda. AIDS Care 2001; 13: 373-85.

[14] Seeley JA, Allison EH. HIV/AIDS in fishing communities: Challenges to delivering antiretroviral therapy to vulnerable groups. AIDS Care 2005; 17: 688-97.

[15] Meekers D. Going underground and going after women: Trends in sexual risk behaviour among gold miners in South Africa. Int $\mathrm{J}$ STD AIDS 2000; 11: 21-6.

[16] Vuylsteke BL, Ghys PD, Traore M, et al. HIV prevalence and risk behavior among clients of female sex workers in Abidjan, Cote d'Ivoire. AIDS 2003; 17: 1691-4.

[17] Cowan FM, Langhaug LF, Hargrove JW, et al. Is sexual contact with sex workers important in driving the HIV epidemic among men in rural Zimbabwe? J Acquir Immune Defic Syndr 2005; 40: 371-6.

[18] Voeten HA, Egesah OB, Ondiege MY, Varkevisser CM, Habbema JD. Clients of female sex workers in Nyanza province, Kenya: A core group in STD/HIV transmission. Sex Transm Dis 2002; 29: 444-52.

[19] Central statistical office [Zambia]. Zambia Demographic and Health Survey 2001-2002. Calverton, Maryland, USA. Central Statistical Office, Central board of health and ORC Macro 2003.

[20] Garenne M, Hohmann-Garenne S. A wealth index to screen highrisk families: Application to Morocco. J Health Popul Nutr 2003; 21: 235-42.

[21] Kreiss JK, Koech D, Plummer FA, et al. AIDS virus infection in Nairobi prostitutes. Spread of the epidemic to East Africa. N Engl J Med 1986; 314: 414-8.

[22] Nagot N, Ouangre A, Ouedraogo A, et al. Spectrum of commercial sex activity in Burkina Faso: Classification model and risk of exposure to HIV. J Acquir Immune Defic Syndr 2002; 29: 517-21.

[23] Lankoande S, Meda N, Sangare L, et al. Prevalence and risk of HIV infection among female sex workers in Burkina Faso. Int J STD AIDS 1998; 9: 146-50. 
[24] Morison L, Weiss HA, Buve A, et al. Commercial sex and the spread of HIV in four cities in sub-Saharan Africa. AIDS 2001; 15: S61-9.

[25] Garenne M, Gakusi E. Vulnerability and resilience: Determinants of under-five mortality changes in Zambia. World Dev 2006; 34: 1765-87.

[26] Celentano DD, Nelson KE, Suprasert S, et al. Behavioral and sociodemographic risks for frequent visits to commercial sex workers among northern Thai men. AIDS 1993; 7: 1647-52.
Leclerc PM, Garenne M. Commercial sex and HIV transmission in mature epidemics. A study of five African countries. Int J STD AIDS, in press.

[28] Sandoy IF, Michelo C, Siziya S, Fylkesnes K. Associations between sexual behaviour change in young people and decline in HIV prevalence in Zambia. BMC Public Health 2007; 7: 60.

[29] Van Rossem R, Meekers D. The reach and impact of social marketing and reproductive health communication campaigns in Zambia. BMC Public Health 2007; 7: 352.

Received: March 24, 2008

(C) Leclerc and Garenne; Licensee Bentham Open.

This is an open access article distributed under the terms of the Creative Commons Attribution License (http://creativecommons.org/licenses/by/2.5/), which permits unrestrictive use, distribution, and reproduction in any medium, provided the original work is properly cited. 